\title{
NNT is a key regulator of adrenal redox homeostasis and steroidogenesis in male mice
}

\author{
E Meimaridou1,*, M Goldsworthy², V Chortis ${ }^{3,4}$, E Fragouli1, P A Foster ${ }^{3,4}$, W Arlt3,4, R Cox ${ }^{2}$ and L A Metherell1 \\ 'Centre for Endocrinology, William Harvey Research Institute, John Vane Science Centre, Queen Mary, University of London, London, UK \\ ${ }^{2}$ MRC Harwell Institute, Genetics of Type 2 Diabetes, Mammalian Genetics Unit, Oxfordshire, UK \\ 3nstitute of Metabolism and Systems Research, University of Birmingham, Birmingham, UK \\ ${ }^{4}$ Centre for Endocrinology, Diabetes and Metabolism, Birmingham Health Partners, Birmingham, UK \\ *(E Meimaridou is now at School of Human Sciences, London Metropolitan University, London, UK) \\ Correspondence should be addressed to E Meimaridou: e.meimaridou@londonmet.ac.uk
}

\section{Abstract}

Nicotinamide nucleotide transhydrogenase, NNT, is a ubiquitous protein of the inner mitochondrial membrane with a key role in mitochondrial redox balance. NNT produces high concentrations of NADPH for detoxification of reactive oxygen species by glutathione and thioredoxin pathways. In humans, NNT dysfunction leads to an adrenal-specific disorder, glucocorticoid deficiency. Certain substrains of C57BL/6 mice contain a spontaneously occurring inactivating $N$ t mutation and display glucocorticoid deficiency along with glucose intolerance and reduced insulin secretion. To understand the underlying mechanism(s) behind the glucocorticoid deficiency, we performed comprehensive RNA-seq on adrenals from wild-type (C57BL/6N), mutant (C57BL/6J) and BAC transgenic mice overexpressing Nnt (C57BL/6JBAC). The following results were obtained. Our data suggest that Nnt deletion (or overexpression) reduces adrenal steroidogenic output by decreasing the expression of crucial, mitochondrial antioxidant (Prdx3 and Txnrd2) and steroidogenic (Cyp11a1) enzymes. Pathway analysis also revealed upregulation of heat shock protein machinery and haemoglobins possibly in response to the oxidative stress initiated by NNT ablation. In conclusion, using transcriptomic profiling in adrenals from three mouse models, we showed that disturbances in adrenal redox homeostasis are mediated not only by under expression of NNT but also by its overexpression. Further, we demonstrated that both under expression or overexpression of NNT reduced corticosterone output implying a central role for it in the control of steroidogenesis. This is likely due to a reduction in the expression of a key steroidogenic enzyme, Cyp11a1, which mirrored the reduction in corticosterone output.

\author{
Key Words \\ - RNA sequencing \\ - nicotinamide nucleotide \\ transhydrogenase \\ - redox homeostasis \\ - steroidogenesis \\ - ROS scavengers
}

\section{Background}

Adrenal insufficiency is a rare, potentially fatal, endocrine disorder resulting from a failure of the adrenal cortex to respond to hormonal stimuli. In familial (or isolated) glucocorticoid deficiency, adrenal hormone output is preserved apart from a specific deficit of glucocorticoids. Normally, under the control of hypothalamic corticotropin-releasing hormone (CRH) and arginine vasopressin (AVP), the pituitary releases adrenocorticotropic hormone (ACTH), which acts on the adrenal via the $\mathrm{ACTH}$ receptor (otherwise known as $M C 2 R$ ) to produce glucocorticoids, mainly cortisol. This in turn acts on the hypothalamus and pituitary to suppress further production
Journal of Endocrinology (2018) 236, 13-28 
of ACTH in a negative feedback loop (Fig. 1A) (Keller-Wood $\&$ Dalman 1984). The human adult adrenal is characterised by three distinctive cortical zones surrounding the medulla; the zona glomerulosa ( $\mathrm{ZG}$ ) where mineralocorticoids are produced, the zona fasciculata (ZF), which synthesises glucocorticoids (mostly cortisol; in mice, the major glucocorticoid is corticosterone) and the zona reticularis (ZR) where androgen synthesis occurs (Vinson 2003). The first step of steroidogenesis occurs once cholesterol is transported from the outer to the inner mitochondrial membrane by the steroidogenic acute regulatory protein (STAR) and is converted to pregnenolone by the cholesterol side chain cleavage enzyme (CYP11A1). To make cortisol, pregnenolone then undergoes a series of intermediate reactions catalysed by microsomal enzymes (CYP17A1, HSD3B2 and CYP21A2) before the final step of cortisol production, catalysed by 11beta-hydroxylase (CYP11B1) or aldosterone production, catalysed by CYP11B2, both occurring in mitochondria (Fig. 1B) (Miller \& Auchus 2011). The activities of steroidogenic cytochrome $P 450$ (CYP) enzymes are reliant upon electron-donating redox partners; for mitochondrial (or type 1) enzymes, electrons are transferred from the reduced form of nicotinamide adenine dinucleotide phosphate (NADPH) by ferredoxin reductase (FDXR) and ferredoxin (FDX1), whereas the microsomal enzymes (Type 2) use P450 oxidoreductase (POR) as their redox partner. Hence, the first and last steps of cortisol production occur in the mitochondria and require a constant supply of reductant NADPH. This $\mathrm{NADPH}$ is regenerated from NADP by a few pathways including the thioredoxin and glutathione pathways, which are ultimately enabled by NNT (Fig. 2).

Perturbations in this pathway cause a number of steroidogenic defects affecting adrenal and gonadal steroidogenesis. STAR mutations give rise to lipoid congenital adrenal hyperplasia (OMIM 201710), a severe syndrome of adrenal and gonadal insufficiency resulting in XY sex reversal; CYP11A1 defects give a similar clinical picture but without the lipid build up in steroidogenic tissues seen with STAR mutations. HSD3B2, CYP17A1, CYP21A2, CYP11B1 and POR mutations give rise to four variants of congenital adrenal hyperplasia (OMIM 201810, 202110, 201910, 202010, and 201750 respectively) and CYP11B2 mutations give rise to hypoaldosteronism (OMIM 203400) (Fig. 1B) (Miller \& Auchus 2011). No mutations have yet been described in humans in FDXR/FDX1 - perhaps due to embryonic lethality. Partial loss-of-function changes in STAR and CYP11A1 can present with a less severe phenotype akin to our disease of interest, familial or isolated glucocorticoid
A

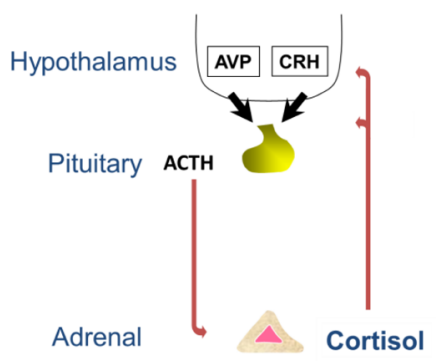

B

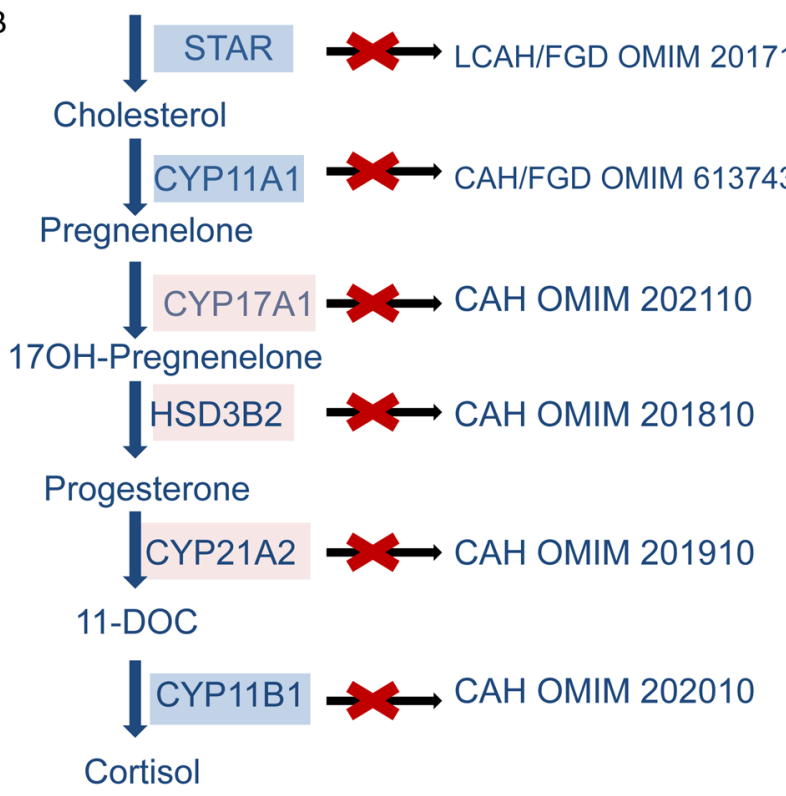

Figure 1

Hypothalamic-pituitary-adrenal (HPA) axis and enzymes responsible for cortisol production. (A) The HPA axis is a major component for adaptation of the stress response and cortisol release and consists of a complex set of feedback interactions that connect the central nervous and endocrine systems. In response to stress the paraventricular nucleus of the hypothalamus releases corticotropin-releasing hormone (CRH) and arginine vasopressin (AVP) that acts on the adrenal to stimulate glucocorticoid synthesis. (B) The conversion of cholesterol to cortisol is achieved by a series of catalytic reactions catalysed by mitochondrial (in blue) and microsomal (in pink) enzymes. Mutations in these key steroidogenic enzymes result in diseases of adrenal and gonadal insufficiency, indicated to the right with their reference numbers from online inheritance in man (OMIM). STAR, steroidogenic acute regulatory protein; CYP11A1, cytochrome P450 side chain cleavage enzyme; CYP17A1, 17-alpha hydroxylase; HSD3B2, 3-beta hydroxysteroid dehydrogenase, CYP21A2, 21-hydroxylase; LCAH, lipoid congenital adrenal hyperplasia; FGD, familial glucocorticoid deficiency; $\mathrm{CAH}$, congenital adrenal hyperplasia.

deficiency (FGD) (Baker et al. 2006, Metherell et al. 2009, Rubtsov et al. 2009, Sahakitrungruang et al. 2010, 2011, Parajes et al. 2011). In FGD, the two most common gene defects are mutations in the melanocortin 2 receptor and its accessory protein (MC2R and MRAP), but recently, we have described defects in NADPH supply to and/or antioxidant defence in mitochondria, with defects in two

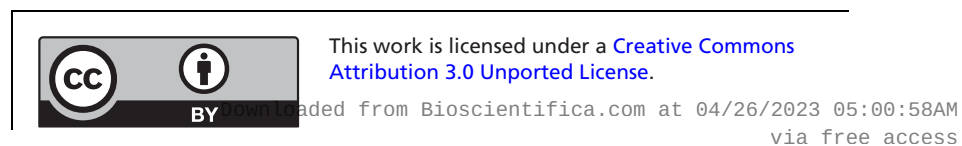




\begin{tabular}{l|l|l|l|l|}
\hline $\begin{array}{l}\text { Journal of } \\
\text { Endocrinology }\end{array}$ & E Meimaridou et al. & $\begin{array}{l}\text { NNT is key for adrenal redox } \\
\text { and steroid control }\end{array}$ & $\mathbf{2 3 6 : 1}$ & $\mathbf{1 5}$ \\
\hline
\end{tabular}

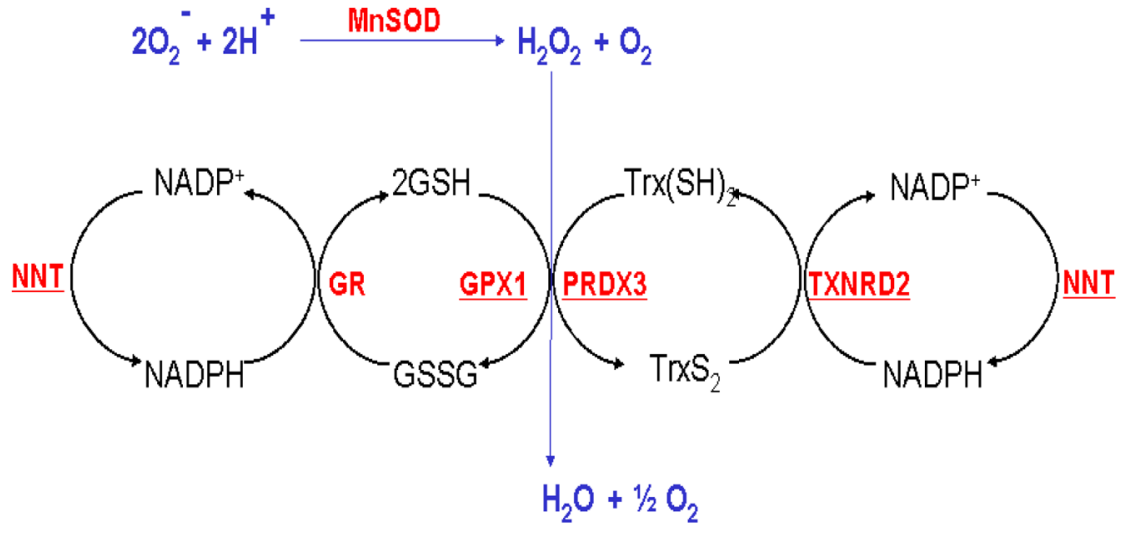

\begin{abstract}
Figure 2
Detoxification of free radicals in the mitochondria. NNT encodes a protein, integral to the inner mitochondrial membrane, which under normal physiological conditions uses energy from the mitochondrial proton gradient to generate high concentrations of NADPH. This is required for many processes in the cell including the supply of reductive power to a network of antioxidant enzymes, specifically the glutathione (GSH/GSSG) and thioredoxin ( $\operatorname{Trx}(\mathrm{SH})_{2} / \mathrm{TrxS}_{2}$ ) systems, to allow the detoxification of $\mathrm{H}_{2} \mathrm{O}_{2}$. Manganese superoxide dismutase (MnSOD) converts $\mathrm{O}_{2}$ - into $\mathrm{H}_{2} \mathrm{O}_{2}$ and protects ROS-sensitive proteins from oxidative damage. $\mathrm{H}_{2} \mathrm{O}_{2}$ is then removed by glutathione peroxidases (e.g. GPX1) or peroxiredoxins (e.g. PRDX3) using GSH and $\operatorname{Trx}(\mathrm{SH})_{2}$ as co-factors. GSH and $\operatorname{Trx}(\mathrm{SH})_{2}$ can be regenerated by glutathione reductase (GR) and thioredoxin reductase-2 (TXNRD2), respectively, using the reducing power from NADPH. Without NNT, the production of NADPH is compromised, causing the mitochondria to become more sensitive to oxidative stress. Enzymes underlined in red are affected by one or more mutations in FGD patients.
\end{abstract}

genes, NNT and thioredoxin reductase 2 (TXNRD2), giving disorders of adrenal insufficiency primarily compromising glucocorticoid production (Meimaridou et al. 2012, 2013, Prasad et al. 2014). MC2R and MRAP are adrenal zone and ACTH pathway specific, so it is unsurprising that they give rise to isolated glucocorticoid deficiency, whereas NNT and TXNRD2 are ubiquitously expressed.

NNT is the major mitochondrial enzymatic source of NADPH contributing $45 \%$ of the total NADPH supply (Nickel et al. 2015). It exists as a dimer and spans the inner mitochondrial membrane modulating $\mathrm{H}^{+}$movement and supplying the high concentrations of NADPH required for the detoxification of ROS by glutathione and thioredoxin pathways (Fig. 2). Even though the gene is ubiquitously expressed, the organ specific physiological roles of NNT are only gradually being revealed by the study of a C57BL/6J mouse substrain that has a spontaneous mutation in Nnt (an in-frame 5-exon deletion), resulting in the truncation of the message and absence of the protein (Nickel et al. 2015). The first consequence of this murine Nnt deletion, described by Toye and coworkers in 2005, was glucose intolerance and reduced insulin secretion (Toye et al. 2005). Subsequent to the finding of human mutations causing FGD, we showed that 3-month-old mice had 50\% lower basal and stimulated levels of corticosterone than their wild-type counterparts. Histological examination of their adrenals revealed a slightly disorganized ZF with higher levels of apoptosis than the wild-type C57BL/6N strain (Meimaridou et al. 2012). More recently, it was reported that liver mitochondria from C57BL/6J mice have major redox impairments resulting in an inability to maintain NADP and glutathione in their reduced states (Ronchi et al. 2013).

Previously, we have shown that H295R cells where Nnt has been stably knocked down undergo oxidative stress as demonstrated by low glutathione levels, and increased mitochondrial superoxide production (Meimaridou et al. 2012). Similar defects in energy metabolism due to Nnt ablation have also been demonstrated in other mouse tissues (heart, liver, pancreas) emphasising the importance of NNT for cellular bioenergetics (Sauer et al. 2004, Ronchi et al. 2013, Nickel et al. 2015). However, the mechanism by which loss of Nnt causes the adrenal-specific pathology we observe is unclear.

Here, we aim to investigate the effect of NNT loss and overexpression in the adrenal cortex by performing RNA-seq on adrenals from mice, which are wildtype $\left(\mathrm{C} 57 \mathrm{BL} / 6 \mathrm{~N}, \mathrm{~N} n t^{+++}\right)$, null $\left(\mathrm{C} 57 \mathrm{BL} / 6 \mathrm{~J}, \mathrm{~N} n t^{-/-}\right)$or 2-fold overexpressors (BAC transgenic, $N n t^{\mathrm{BAC}}$ ) of $\mathrm{N} n t$ (Freeman et al. 2006).

\section{Materials and methods}

\section{Mouse strains}

All mice were bred, housed and culled at MRC Harwell and therefore the husbandry was identical for all 3 substrains. The mouse strains used were C57BL/6NHsd originally

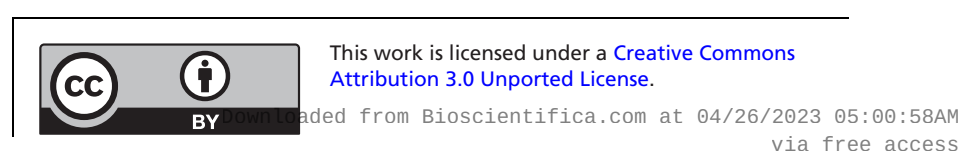


from Harlan (Harlan Laboratories UK), which is wild type for Nnt $\left(\mathrm{N}^{++/+}\right), \mathrm{C} 57 \mathrm{BL} / 6 \mathrm{~J}$ originally from Charles River (Charles River UK), which has an in-frame deletion of

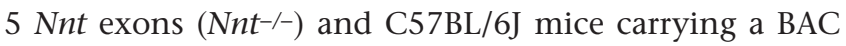
transgene to restore murine $N n t$ ( $N n t^{B A C}$; Freeman et al. 2006), which we show are 2 -fold overexpressors. For RNA-seq, 18-month-old male mice of the three different substrains were utilised, 5 mice per group. Mice were culled with an overdose of Euthatal (to allow for the collection of blood) and tissues were then removed quickly and either fixed or flash frozen in liquid nitrogen. All mice were culled between 10:00 and 11:30 $\mathrm{h}$ and adrenals were removed. The animal protocols used in this study were approved by United Kingdom Home Office.

\section{Genotyping}

Genomic DNA was extracted from the mouse tail tissue using a Qiagen DNeasy tissue kit. Mice were genotyped for Nnt status using previously published primers (Huang et al. 2006).

\section{Mouse histology}

Mouse adrenals from $N n t^{+/+}, N n t^{-/-}$and $N n t^{B A C}$ were fixed in $4 \%$ paraformaldehyde (Sigma) and embedded in paraffin. Sections were obtained using a microtome (Microm HM 325, Thermo Fisher) at 6- $\mu$ m thickness, and hematoxylin \& eosin (H\&E) staining was performed using standard procedures (Guasti et al. 2011).

To assess changes in lipid content between the three mice strains, we performed Oil Red O staining as described previously (www.ihcworld.com/_protocols/special_stains/ oil_red_o.htm). Briefly sections of fresh frozen adrenal tissues were obtained at $5 \mu \mathrm{m}$ thickness and fixed in ice cold $10 \%$ formalin for $5 \mathrm{~min}$. Sections were air dried and placed in absolute propylene glycol for $5 \mathrm{~min}$ to avoid carrying water into Oil Red O. Sections were then stained with pre-warmed Oil Red $\mathrm{O}$ solution for $8-10 \mathrm{~min}$ at $60^{\circ} \mathrm{C}$ and then washed twice with distilled water. Images were acquired using a Leica DMR microscope (Leica), and digital images were captured using a Leica DC200 camera (Leica) and DCViewer software (Leica).

\section{Steroid profile}

Serum steroids were quantified using liquid chromatography-tandem mass spectrometry (LC-MS/MS) as previously described (O'Reilly et al. 2014). Steroids were extracted from $200 \mu \mathrm{L}$ of serum (after addition of internal standard) using $1 \mathrm{~mL}$ tert-butyl methyl ether (MTBE). After freezing at $-20^{\circ} \mathrm{C}$ for $1 \mathrm{~h}$, the MTBE layer was transferred into a 96-well plate and evaporated under nitrogen at $55^{\circ} \mathrm{C}$. Samples were reconstituted in $125 \mu \mathrm{L}$ of a $50: 50$ solution of methanol (Sigma) and $\mathrm{H}_{2} \mathrm{O}$ (Sigma). Steroids were analysed on a Waters Xevo with Acquity uPLC, steroids were eluted from a HSS T3 $1.8 \mu \mathrm{m}, 1.2 \times 50 \mathrm{~mm}$ column with a methanol/water $0.1 \%$ formic acid gradient system. Two mass transitions were used to identify and quantify each steroid (corticosterone: 347.2>121.2 and 347.2>97; deoxycorticosterone: 331>97 and 331>109.

\section{Generation of stable NNT knockdown (KD) and scrambled (SCR) H295R cell lines}

Lentiviral plasmids (RHS4430-98851990; RHS443098913600; RHS4430-98524425; RHS4430-101033169 RHS4430-101025114) were obtained from OpenBiosystems in a p.GIPZ backbone and contained shRNA specific for human NNT (NM 012343) under the control of the CMV promoter, plus the puromycin resistance and green fluorescence protein (GFP) genes. HEK293T cells (packaging cells) were transiently transfected with the shRNA plasmids, two days after transfection virus containing media was collected, filtered using a $0.22 \mu \mathrm{m}$ filter and used to transduce H295R cells. Four days after infection GFP-positive cells were selected in $4 \mu \mathrm{g} / \mathrm{mL}$ puromycin. Transduction efficiency was determined by fluorescence microscopy. A scrambled (control) cell line was generated in a similar fashion using a non-specific shRNA.

\section{NADP/NADPH assay}

To measure total and reduced nicotinamide adenine dinucleotide phosphates (NADP+ and NADPH respectively) stably transfected H295R cells were plated onto white-walled and white bottomed 96-well culture dishes (Corning Costar). After 24h, NADP+ and NADPH were measured using NADP/NADPH-Glo assay (Promega), a luminescence-based system and according to the manufacturer's protocol. Luminescence was recorded after 15 min using Omega Luminometer (BMGLabTech) and with integration time of $0.5 \mathrm{~s}$.

\section{Oxygen consumption rate-XF extracellular flux analyser}

Scrambled (SCR) and stable knockdown H295R cells (NNT-KD) were cultured on Seahorse XF-96 microplates

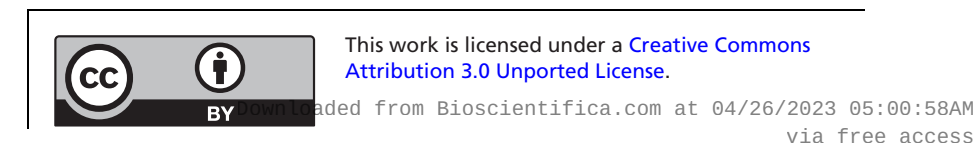


and allowed to grow overnight. On the day of metabolic flux analysis, cells were changed to unbuffered DMEM (DMEM base medium supplemented with $10 \mathrm{mM}$ glucose, $1 \mathrm{mM}$ sodium pyruvate, $2 \mathrm{mM}$ L-glutamine, $\mathrm{pH}$ 7.4) and incubated at $37^{\circ} \mathrm{C}$ in a non- $\mathrm{CO}_{2}$ incubator for $1 \mathrm{~h}$. All medium and injection reagents were adjusted to $\mathrm{pH} 7.4$ on the day of assay. Baseline measurements of oxygen consumption rate (OCAR, measured by oxygen concentration change) and extracellular acidification rate (ECAR, measured by $\mathrm{pH}$ change) were taken before sequential injection of treatments/inhibitors: oligomycin (ATP synthase inhibitor, $4 \mu \mathrm{M}$ ), FCCP (mitochondrial respiration uncoupler, $1 \mu \mathrm{M}$ ) and rotenone (Complex I inhibitor, $1 \mu \mathrm{M})$.

\section{RNA-seq}

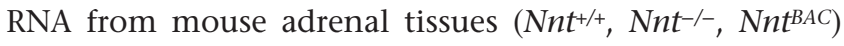
was extracted using the RNeasy Mini kit (Qiagen). Once RNA quality and concentration were tested, samples were processed by Oxford Gene Technology (www.ogt.co.uk). Enrichment and library preparation were performed using Illumina TruSeq RNA Sample Prep Kit, v2; total RNA was captured with oligo-dT-coated magnetic beads. The mRNA was fragmented and then first-strand cDNA synthesis was initiated from random primers, followed by secondstrand synthesis. After end-repair, phosphorylation and A-tailing, adapter ligation and PCR amplification were performed to prepare the library for sequencing. Pairedend sequencing was performed over 100 cycles on the Illumina HiSeq2000 platform using TruSeq v3 chemistry. Fastq files were generated from the sequencing platform via the manufacturer's proprietary software. For mapping and alignment, reads were processed through Tuxedo suite (Trapnell et al. 2013). Reads were mapped to their location on the appropriate Illumina iGenomes build using Bowtie, and splice junctions were identified using Tophat. Cufflinks was used to perform transcript assembly, abundance estimation and differential expression and regulation for the samples. RNA-Seq alignment metrics were generated using Picard.

\section{Lipid peroxidation assay}

Lipid peroxidation in mouse adrenal lysates was assessed by using a lipid peroxidation assay kit (Abcam) based on the detection of malondialdehyde (MDA) in the samples.

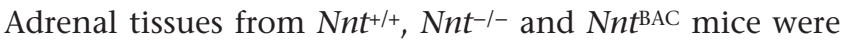
excised and homogenised in MDA lysis buffer provided in the kit. Lysates were then centrifuged at $13,000 \boldsymbol{g}$

$$
\text { http://joe.endocrinology-journals.org }
$$

for $10 \mathrm{~min}$ and the supernatant was collected for lipid peroxidation measurements. Samples were incubated with thiobarbituric acid (TBA), which interacts with MDA present in the samples to generate MDA-TBA adducts. These adducts were quantified colorimetrically at $532 \mathrm{~nm}$.

\section{Immunoblotting analysis}

Immunoblotting was used to assess protein expression. Cells were lysed in RIPA buffer containing protease and phosphatase inhibitors (SIGMA) and then left on ice for $30 \mathrm{~min}$. Samples were centrifuged for $15 \mathrm{~min}$ at $17,000 \boldsymbol{g}$. Supernatant was collected and an equal volume of Laemmli buffer was added. Samples were heated at $95-100^{\circ} \mathrm{C}$ for $5 \mathrm{~min}$ and then loaded on $4-12 \%$ SDS gels. Protein separation was performed by using the Invitrogen electrophoresis system. Proteins were then transferred to nitrocellulose membrane (Sigma Aldrich) using semi-dry transfer blot (Biorad) at $15 \mathrm{~V}$ for $1 \mathrm{~h}$. Membranes were probed with one of mouse anti-Nnt (1:1000; SIGMA, HPA004829), mouse anti-actin (1:5000; SIGMA, A5441), rabbit anti-TXNRD2 (1:1000;SIGMA, SAB2702064), rabbit anti-PRDX3 (1:500; ProteinTech, 55087-1-AP), rabbit anti-GPX1 (1:500; Abcam ab108429), mouse anti-STAR (1:1000; Abcam, ab58013), rabbit anti-CYP11A1 (1:1000; Cell Signalling, 14217), rabbit anti-HSD3B2 (1:500; Aviva Biosystems, OAGA02009) or rabbit anti-CYP21A2 (1:500; SIGMA HPA053371). Visualisation of the proteins was performed by using Alexa-Fluor 680 and 800 secondary antibodies (1:5000; Invitrogen) and the Li-CoR Odyssey system.

\section{Statistics}

Statistical analyses were performed using a combination of one-way ANOVA using Tukey HSD (honest significant difference) test and a two-tailed Student's $t$-tests assuming unequal variance in 5 mice per group. All values were expressed as a mean \pm s.E.M., and $P$ values $<0.05$ were considered significant.

\section{Results}

\section{Mouse phenotyping}

We have previously reported that 3-month-old mice carrying a spontaneous Nnt 5-exon deletion (C57BL/6J, $\mathrm{N}^{-\mathrm{I}^{-}}{ }^{-}$) have significantly lower levels of corticosterone $(50 \%)$ than their wild-type counterparts (C57BL/6N, $N n t^{+++}$) (Meimaridou et al. 2012). To identify the

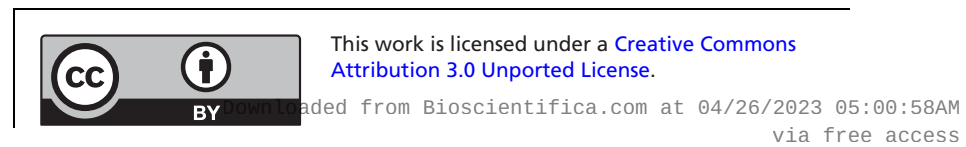


mechanism by which loss of NNT affects steroidogenesis we employed the same mouse models but also included an additional mouse line where the Nnt loss had been rescued in $\mathrm{C} 57 \mathrm{BL} / 6 \mathrm{~J}$ mice by transgenic expression of the entire murine Nnt gene contained within a bacterial artificial chromosome (BAC transgenic, $N n t^{\mathrm{BAC}}$ ) (Freeman et al. 2006).

\section{Glucocorticoid levels in the three mouse strains}

The adrenal steroid output of the three mouse strains was measured at 18 months in murine serum samples employing liquid chromatography-tandem mass spectrometry (LC-MS/MS). Changes in steroid production were observed predominantly for corticosterone, with

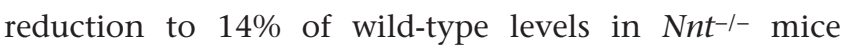

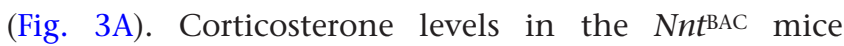
restored serum corticosterone in part, but only to $40 \%$ of wild-type $\left(\mathrm{Nnt}^{+++}\right)$levels, suggesting that overexpression of Nnt also perturbs steroidogenesis. 11-Deoxycorticosterone levels were not significantly different among the mice and therefore the ratio of 11-deoxycorticosterone/ corticosterone was significantly higher in $\mathrm{Nnt}^{-1-}$ and $N n t^{\mathrm{BAC}}$ mice indicating lower enzyme activity of $C y p 11 b 1$ (Fig. 3B). We also noted that, over time, the deficit in glucocorticoid output worsened for the $\mathrm{Nnt}^{-1-}$ mice,

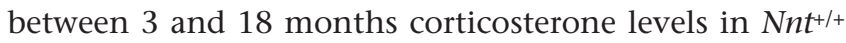
were unaltered, whereas there is a $60 \%$ decrease for $\mathrm{N}^{-1-} \mathrm{I}^{-}$ mice, suggesting progressive loss of function (Fig. 3C).

\section{No changes to adrenal histology}

In humans with FGD, there is a specific loss of glucocorticoid output from the ZF and relative preservation of steroid output from the other zones suggesting loss of this specific zone. Consistent with
A

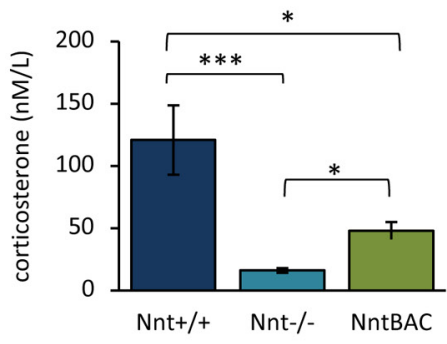

B

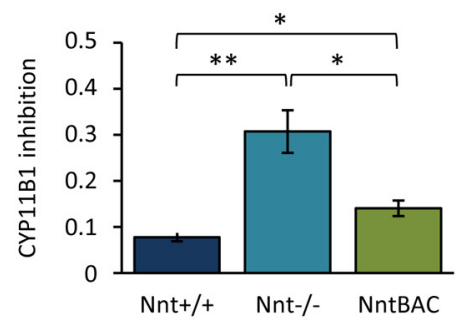

C

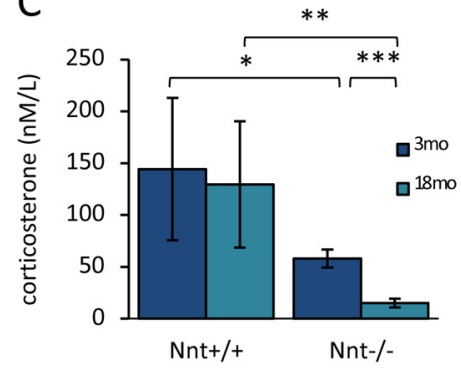

D

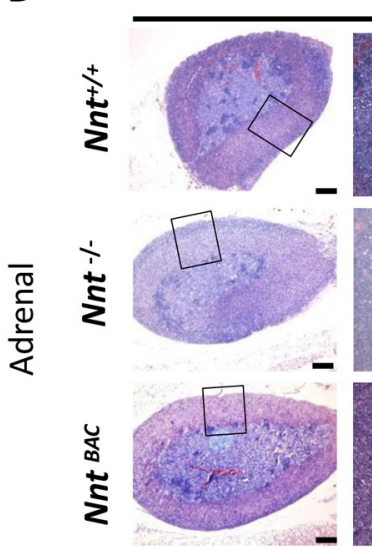

H\&E staining
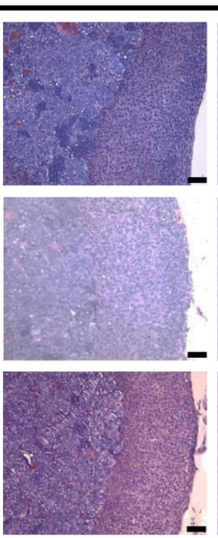
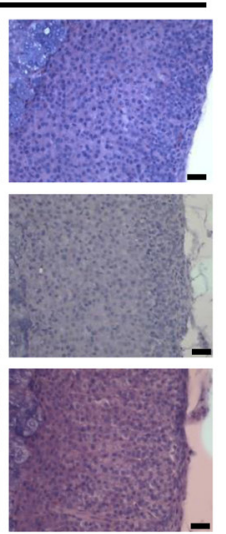

$\mathrm{E}$

Oil Red O staining

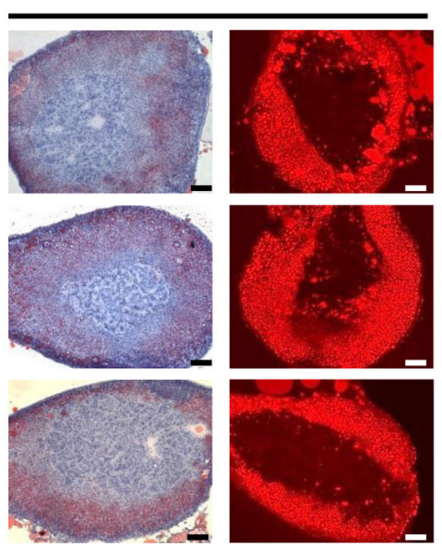

Figure 3

Biochemical and phenotypic characterisation of $\mathrm{Nnt}^{+/+}, \mathrm{Nnt}^{-l_{-}}$and $\mathrm{Nnt^{BAC }}$ mice. (A) Serum corticosterone in $\mathrm{Nnt}^{+/+}, \mathrm{Nnt}^{-/-}$and $\mathrm{Nnt}^{\mathrm{BAC}}$ mice was measured by LC-MS/MS and showed $80 \%$ and $50 \%$ reduction in $\mathrm{Nnt}^{-1-}$ and $\mathrm{Nnt}^{\mathrm{BAC}}$ mice, respectively. (B) The 11-deoxycorticosterone (DOC)/corticosterone ratio (CYP11B1 inhibition) was significantly higher in $\mathrm{Nnt}^{-/-}$and $\mathrm{Nnt}^{\mathrm{BAC}}$ than $\mathrm{Nnt}^{+/+}$mice. (C) Corticosterone synthesis deteriorates in 18 months $\mathrm{Nnt}^{-/-}$mice whereas there is no significant difference in the levels between 3 and 18 month $\mathrm{Nnt}^{+/+}$mice. (D) H\&E staining of mouse adrenals showed no major histological differences in architecture or zonation (left panel) and (E) Oil Red O staining revealed no difference in lipid content of the adrenals among the three mouse strains (right panels). Results are means \pm standard deviation (s.D.); $n=5$ mice per group, $* P<0.05, * * P<0.01, * * \star P<0.001$.

http://joe.endocrinology-journals.org https://doi.org/10.1530/JOE-16-0638
() 2018 The authors Published by Bioscientifica Ltd. Printed in Great Britain

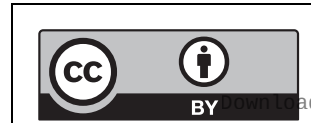

This work is licensed under a Creative Commons Attribution 3.0 Unported License. 
these findings, $M c 2 r^{-1-}$ mice have smaller adrenals with preservation of ZG and medulla but atrophied ZF (Chida et al. 2007). Interestingly all $M c \mathrm{Cr}^{-1-}$ mice on a pure C57BL/6J background die within two days of birth whereas those on a mixed $\mathrm{B} 6 / \mathrm{Balbc}$ have much higher survival rates, with half making it to adulthood perhaps due to the restoration of Nnt levels (Chida et al. 2009), making Nnt a genetic modifier of their adrenal phenotype akin to the situation in another mouse model where NNT has a protective role in superoxide dismutase deficient mice (Huang et al. 2006). To determine whether loss of ZF occurs in $\mathrm{Nnt}^{-/-}$mice we performed $\mathrm{H} \& \mathrm{E}$ staining in adrenal sections from the three mouse substrains. This showed no morphological differences among the strains in adrenal zonation (Fig. 3D). This was supported by the finding that genes differentially expressed between zones were not altered (see below). This suggested no major remodelling of the adrenals due to NNT loss and gave us confidence that the RNA-seq variations were not due to changes in zonation. Furthermore, on Oil Red O staining, we observed no differences in lipid levels between the mouse strains suggesting there is neither a dearth of cholesterol supply for steroidogenesis nor a surplus due to a cholesterol transport defect as seen with Star mutations (Sasaki et al. 2008) (Fig. 3E).

\section{Nnt deletion causes oxidative stress in mouse adrenals}

We measured lipid peroxidation (LPO) by a malondialdehyde (MDA) assay as a measure of oxidative stress in these mice ( 5 mice per group). There was a significant increase in LPO in the adrenals of $\mathrm{Nnt}^{-1-}$ mice which returned towards wild-type levels in $\mathrm{Nnt}^{\mathrm{BAC}}$ mice indicating lipid damage by free radicals in adrenals upon Nnt deletion (Fig. 4A). We saw the same trend in $\mathrm{H}_{2} \mathrm{O}_{2}$ levels (increased in $\mathrm{Nnt}^{-/-}$and reduced again in $\mathrm{Nnt}^{\mathrm{BAC}}$ ) (data not shown).

Impaired redox homeostasis caused by lack of NNT was further supported by in vitro studies in human adrenocortical H295R cells. The total cellular NADP/ NADPH ratio was significantly higher in H295R with lentiviral knockdown of NNT (NNT-KD) compared to scrambled control cells (SCR), suggesting that NNT is required to maintain the redox state of the intracellular $\mathrm{NADPH}$ and NADP+ pools (Fig. 4B).

The perturbation in NADP/NADPH balance affected mitochondrial respiration resulting in significantly lower oxygen consumption rates (OCAR) in cells where NNT is knocked down (Fig. 4C).

$$
\begin{aligned}
& \text { http://joe.endocrinology-journals.org } \\
& \text { https://doi.org/10.1530/JOE-16-0638 }
\end{aligned}
$$
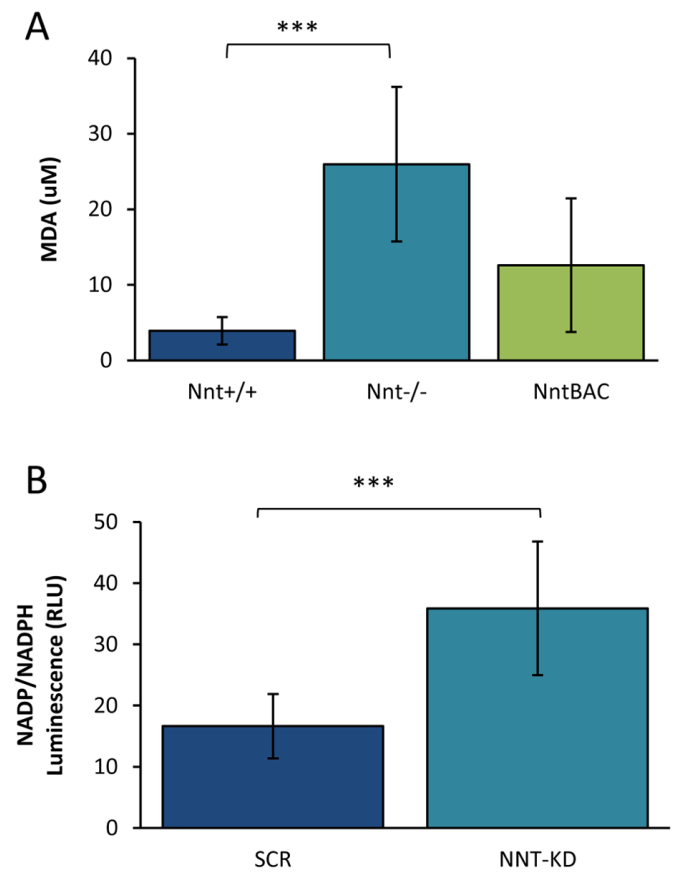

C

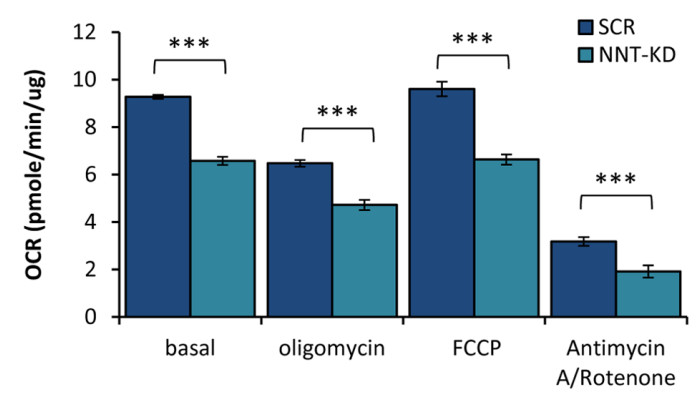

Figure 4

Oxidative stress on NNT ablation. (A) Lipid peroxidation represented by MDA levels were measured in adrenals of $\mathrm{Nnt}^{+/+}, \mathrm{Nnt}^{-1-}$ and $\mathrm{Nnt}^{\mathrm{BAC}}$ mice. MDA levels were significantly increased in the adrenals of $\mathrm{Nnt}^{-l-}$ mice with a partial rescue in $\mathrm{Nnt}^{\mathrm{BAC}}$ mice indicating lipid damage by free radicals in adrenals upon Nnt deletion (B) The cellular levels of NADP/ NADPH in H295R cells with a stable knockdown of NNT (NNT-KD) were measured by using a luciferin based assay. Total cellular NADP/NADPH ratio was significantly higher in NNT-KD compared to scramble (SCR), suggesting that NNT is required to maintain the redox state of the intracellular NADPH and NADP+ pools. (C) Mitochondria respiration was assessed by measuring oxygen consumption rates using Seahorse XF-96 metabolic Flux Analyser. NNT-KD cells had a significantly lower basal OCAR compared to scrambled cells; the addition of oligomycin (complex $V$ inhibitor) resulted in an OCAR decline which was significantly lower in NNT-KD cells compared to controls, indicating that the ATP turnover was compromised in NNT-KD cells. Furthermore, maximal respiration capacity as measured by the addition of an uncoupling agent, FCCP, was also significantly lower in NNT-KD cells. The addition of rotenone and antimycin (complex I and II inhibitors respectively) reflecting the spare respiratory capacity of the cells resulted in a reduction of OCAR which was significantly lowered in NNT-KD cells when compared to scrambled cells. OCAR values were normalised to total protein concentration. Results are means \pm standard deviation (s.D.); $n=5$ per group, $* P<0.05, * * P<0.01, * * * P<0.001$.

This work is licensed under a Creative Commons Attribution 3.0 Unported License. 
Transcriptome profiling by RNA-seq in adrenals from the C57BL/6 mouse substrains

To investigate the cause of the reduced steroid production upon Nnt deletion, RNA was extracted from $N n t^{+/+}, N n t^{-/-}$, and $N n t^{\mathrm{BAC}}$ mouse adrenals and the transcriptome profiled by RNA-seq. Using an Illumina HiSeq 2000 sequencer we obtained an average of 30 million reads per sample, with $\sim 98 \%$ of these reads mapped to the mouse reference genome. In total,

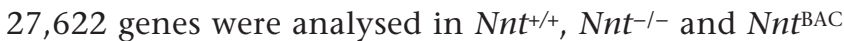
adrenals (Fig. 5A and Supplementary Table 1, see section on supplementary data given at the end of this article). The most highly expressed categories of genes were mitochondrially encoded electron transport chain genes (mt-Co1, mt-Co2, mt-Atp6, mt-Co3, mt-Cytb, mt-Nd4, mt-Nd2, mt-Nd1, mt-Atp8, mt-Nd6, mt-Nd5, mt-Nd4l, $m t-N d 3, m t-R n r 1)$, followed by steroid pathway genes Star, Cyp21a1 and Hsd3b1, which are high up in the steroidogenic cascade (Supplementary Table 1) perhaps reflecting the high mitochondrial content of and high demand for steroidogenesis in the adrenal.

Initial data analysis was performed between paired

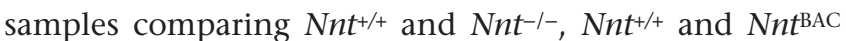
and $N n t^{-/-}$and $N n t^{\mathrm{BAC}}$ adrenals. To identify differentially expressed genes from each group we used the following criteria; (1) gene expression level greater than or equal to 1 read per kilobase of exon per million fragments mapped (RPKM) in all samples; (2) change in expression level greater than or equal to 1.5 -fold; and (3) significance $P$ value $<0.05$. This revealed differential expression (fold change $\geq 1.5 ; P<0.05$ ) of 400 genes in total in the pairwise comparisons (Fig. 5B, C and Supplementary Table 2). Only 1 gene varied between all three pairwise analyses and that was Nnt itself (see below and Fig. 5C). We hypothesized that genes that were up- or downregulated in $\mathrm{Nnt}^{-/-}$and their levels restored in $N n t^{B A C}$ would be genes that were modulated by NNT.

\section{NNT levels in the three mouse strains}

Nnt expression levels in the three mouse strains were determined and while we observed very low mRNA levels in $\mathrm{N}^{-{ }^{-/}}$mice (3.7-fold downregulation $P=0.012$ ), there was a 2.7 -fold $\left(P=1.8 \times 10^{-5}\right)$ increase in Nnt expression in $N n t^{\mathrm{BAC}}$ mice over that for $\mathrm{N}^{++/+}$(Fig. 6A). To investigate whether mRNA levels corresponded to protein expression we performed a Western blot on adrenal lysates from the
A

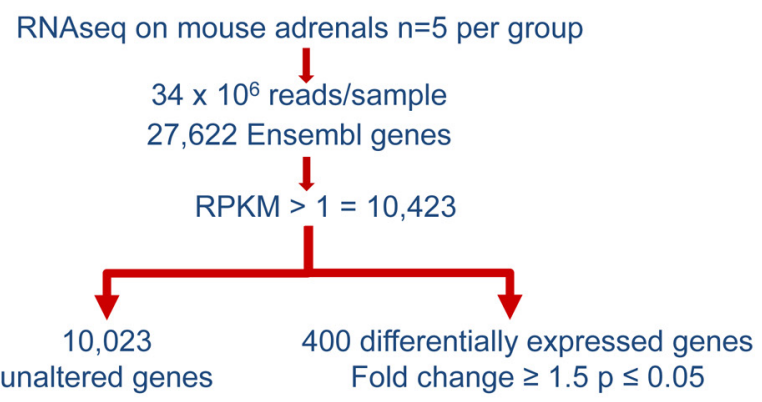

B

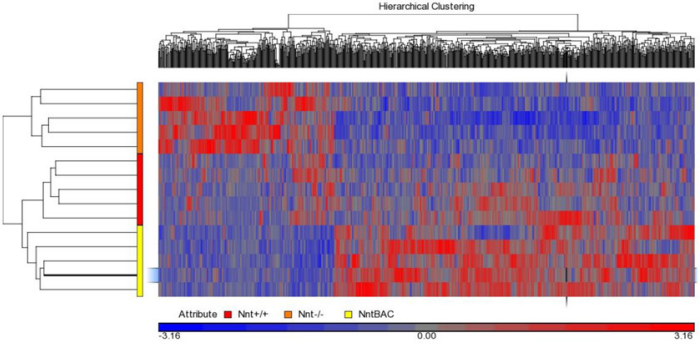

C

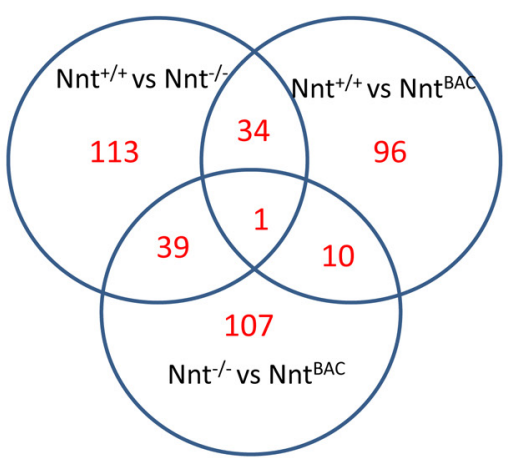

Figure 5

RNA-seq analysis flowchart and differential gene expression.

(A) Flowchart of initial RNA-seq analysis of mouse adrenals.

(B) Representative heat map of RNA-seq analysis for substrain-specific

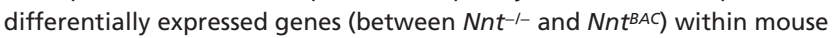
adrenals. Genes were clustered by Partek hierarchical clustering based on gene expression values. Normalisation was performed by genes shifted to mean of zero and scaled to S.D. of 1. Arbitrary signal intensity from RNA-seq data is represented by colours (red, higher expression, blue lower expression). (C) Venn diagram showing the number of differential genes in pairwise analyses between; $\mathrm{Nnt}^{+/+}$vs $\mathrm{Nnt}^{-I_{-}^{-}}$(187), $\mathrm{Nnt}^{-I_{-}^{-}}$vs $\mathrm{Nnt}^{\mathrm{BAC}}$ (157) and $N n t^{+/+}$vs $N n t^{B A C}(141)$. Genes at the intersection of the pairwise analyses $\mathrm{Nnt}^{+/+}$vs $\mathrm{Nnt}^{-I_{-}}$and $\mathrm{Nnt}^{-I_{-}}$vs $\mathrm{Nnt}^{\mathrm{BAC}}$ represent genes that are modulated by $N n t$ levels $(39+N n t)$ (Table 1 and Supplementary Tables 3, 4, 5, 6, 7 and 8).

same mice. NNT was undetectable in the $\mathrm{Nnt}^{-/-}$mice whereas a two-fold increase in NNT was observed in the adrenals of $N n t^{\mathrm{BAC}}$ mice, in keeping with the RNA-seq data (Fig. 6B). These results suggest that the $N n t^{\mathrm{BAC}}$ represents a modest Nnt overexpressor. 
A

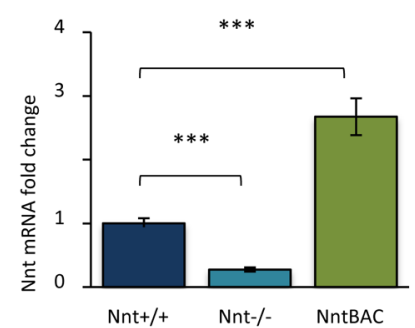

C

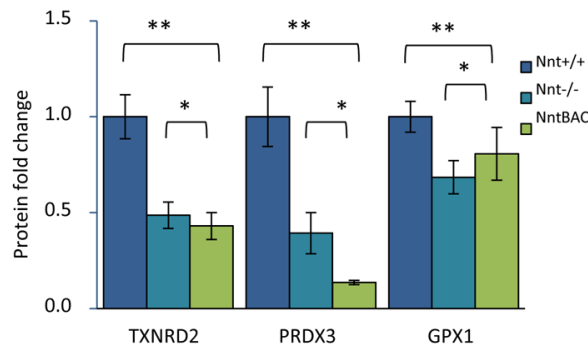

B

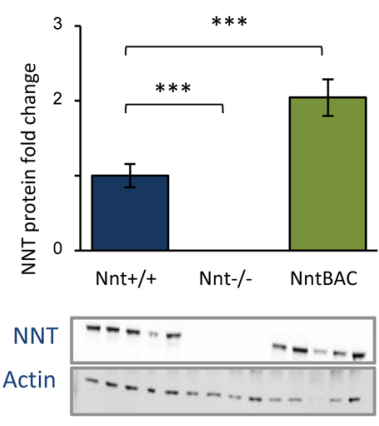

D

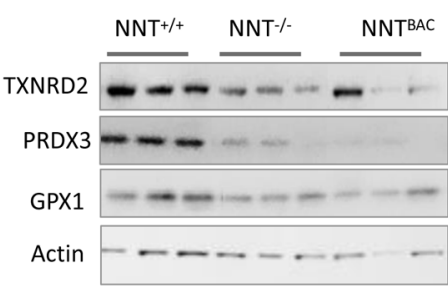

Figure 6

Effect of NNT loss on redox homeostasis. (A) mRNA Nnt levels in the three mouse strains. (B) No NNT protein expression was observed in Nnt $^{-1-}$ (Western blot) however there was a two-fold upregulation in NntBAC when compared to $\mathrm{Nnt}^{+/+}$. (C) Protein levels of TXNRD2, PRDX3 and GPX1 in the $\mathrm{Nnt}^{+/+}, \mathrm{Nnt}^{-l_{-}}$and $\mathrm{Nnt}^{\mathrm{BAC}}$ mouse adrenals were normalised to actin with representative Western blots shown to the right.
No differential expression of other genes with polymorphisms identified between substrains

Recently, comparative genomics between C57BL/6J and C57BL/6N strains has identified many SNPs and structural variants that may contribute to the phenotypic differences between the two strains (Simon et al. 2013). To check whether these SNPs altered expression of these genes in the adrenal we specifically looked at their mRNA expression levels. Except for Cilp, which was up in Nnt ${ }^{\mathrm{BAC}}$ (1.6 fold over $\mathrm{Nnt}^{+/+}(P$ 0.013)) but unaltered between $\mathrm{N} n \mathrm{t}^{+/+}$and $\mathrm{N} n \mathrm{t}^{-/-}$, we found no alterations in expression levels of the genes with interstrain variations, suggesting that the effects we describe are largely due to differential Nnt levels.

\section{No differential expression of zone specific genes} between substrains

Many genes show differential expression between the zones of the adrenal, classically for example tyrosine hydroxylase (Th), aldosterone synthase (Cyp11b2), 3-betahydroxysteroid dehydrogenase (Hsd3b2), cytochrome b5 (Cyb5) and aldo-keto reductase family 1 member C3 (Akr1c3). More recently transcriptomic analyses have identified hundreds of other genes with differential expression between ZF and ZG (Nishimoto et al. 2012, Rege et al. 2014). None of these genes showed differential expression in our study suggesting no major remodelling of adrenals glands in $\mathrm{Nnt}^{-/-}$or $\mathrm{Nnt}^{\mathrm{BAC}}$ mice.
Nnt deletion does not alter the levels of ACTH receptor pathway genes or other genes associated with adrenal insufficiency

Mc2r expression was unaltered between $\mathrm{Nnt}^{+/+}$vs $\mathrm{Nnt}^{-/-}$ but up in $N n t^{B A C}$ vs ${\mathrm{N} n t^{-/-}}^{-}(1.6$-fold $P=0.023)$ whereas Mrap levels were the same across the 3 groups (data not shown). No significant expression level changes were observed at RNA level for other genes causing adrenal insufficiencies in humans (Aaas, Abcd1, Aire, Cdkn1c, Cyp11a1, Cyp11b1, Cyp17a1, Cyp21a1, Mcm4, Nr5a1, Por and Txnrd2).

\section{Nnt deletion alters antioxidant gene levels}

Nnt provides a constant supply of NADPH required for ROS detoxification by the thioredoxin and glutathione systems. Malic enzyme $3(\mathrm{Me} 3)$ and isocitrate dehydrogenase 2 (Idh2) are alternate NADPH suppliers although NNT is the major contributor (14). To investigate whether Nnt deletion leads to perturbation of other antioxidant enzymes perhaps to compensate for its loss, we looked at the mRNA and protein levels of antioxidant enzymes in these pathways. There was a modest reduction in gene expression levels of the antioxidants Prdx3 and Txnrd2 which did not reach statistical significance, however at the protein level they were significantly reduced in $N n t^{-/-}$mice vs $\mathrm{N} \mathrm{t}^{+/+}$and the levels remained significantly low in $N n t^{\mathrm{BAC}}$ when compared to $N t^{+/++}$(Fig. $6 \mathrm{C}$ and D). This is likely because $N n t^{\mathrm{BAC}}$ overexpress NNT which may also cause redox imbalance, implying fine tuning 
of NNT is required for redox homeostasis. We observed no compensatory increase in the alternative NADPH suppliers Me3 or $\operatorname{Idh} 2$.

\section{Nnt deletion alters mitochondrial cytochrome P450scc levels}

STAR is a protein involved in the transport of cholesterol from the outer to the inner mitochondrial membrane and specific partial loss-of-function mutations in STAR account for 10\% of FGD cases (Meimaridou et al. 2013). Similarly, "mild" mutations in the cholesterol side chain cleavage enzyme (CYP11A1, the first enzyme in the steroid pathway), can give rise to FGD (Rubtsov et al. 2009,
Parajes et al. 2011, Sahakitrungruang et al. 2011). Mutations in 11 -hydroxylase (CYP11B1, the last enzyme in the glucocorticoid pathway) cause congenital adrenal hyperplasia. Previous work revealed that oxidative stress, resulting from the application of exogenous ROS, lead to inhibition of STAR protein expression and steroidogenesis in MA-10 Leydig cells, with no effect on CYP11A1 (Diemer et al. 2003). We hypothesized that a similar phenomenon might occur with endogenous mitochondrial oxidative stress resulting from NNT deficit affecting Star and/or the mitochondrial CYP450 enzymes, Cyp11a1 and Cyp11b1/b2. RNA-seq and Western blot analysis showed no significant changes in the expression of Star at mRNA or protein level, indicating that a defect in cholesterol

A

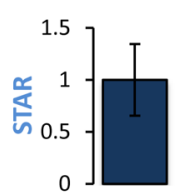

RNA fold Change

Protein Fold Change
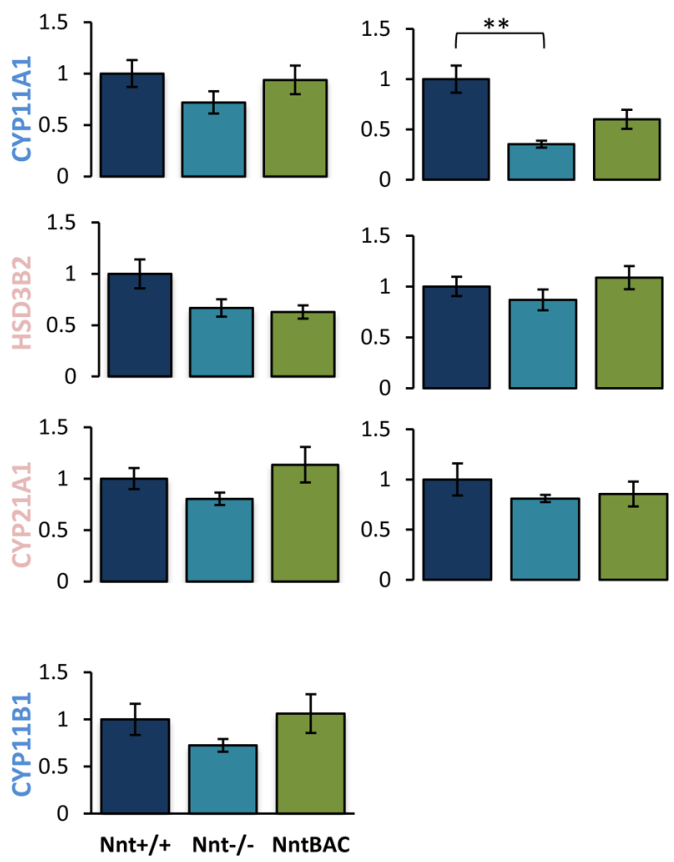

Nnt+/+ Nnt-/- NntBAC

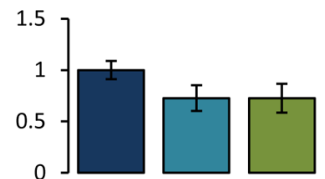

B

C
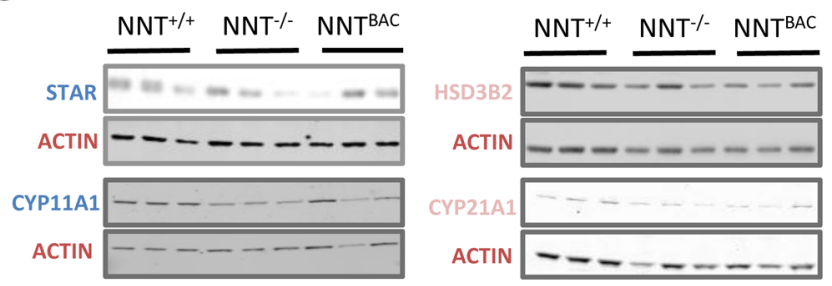

http://joe.endocrinology-journals.org http://joe.endocrinology-journals.org
https://doi.org/10.1530/JOE-16-0638

(C) 2018 The authors Published by Bioscientifica Ltd. Printed in Great Britain

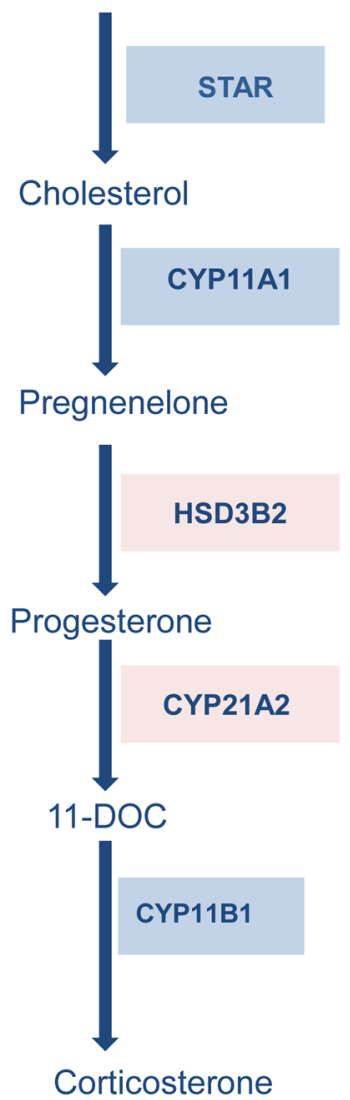

holesterol

gnenelone

Corticosterone
Figure 7

Effect of NNT loss on steroidogenesis. (A) mRNA and protein fold change of enzymes involved in glucocorticoid synthesis, starting from cholesterol transport (STAR), to the first step of steroid synthesis (mitochondrial CYP11A1), and subsequent reactions catalysed by microsomal enzymes (HSD3B2, CYP21A1) to the final synthesis of corticosterone. (B) The conversion of cholesterol to corticosterone in mice is achieved by a series of catalytic reactions catalysed by mitochondrial (in blue) and microsomal (in pink) enzymes (right panel). (C) Panel of Western blots representing changes in expression of protein involved in steroidogenesis. Results are means \pm standard deviation (s.D.); $n=5$ mice per group, ${ }^{*} P<0.05, * * P<0.01, * * * P<0.001$. 
transport due to oxidative insult is an unlikely mechanism (Fig. 7A and C). However, a suggestive 25\% decrease in Cyp11a1, Cyp11b1 and Cyp11b2 mRNA levels in Nnt--- mice with incomplete recovery in $N n t^{\mathrm{BAC}}$ suggested a possible mechanism for steroid depletion. In agreement with this we observed a $65 \%$ reduction in CYP11A1 at protein level in $\mathrm{N}^{-/-}$and partial restoration (to approx. $50 \%$ of $\mathrm{N}^{+/ /+}$ levels) in $\mathrm{Nnt}^{\mathrm{BAC}}$ (Fig. 7A and C). We were unable to assess CYP11B1/B2 levels since no specific murine antibody exists. The failure to completely recover Cyp11a1 levels in the $N t^{\mathrm{BAC}}$ mice may be due to redox imbalance in these overexpressing mice and, significantly, protein abundance mirrors the levels of corticosterone in the three mouse substrains (Figs 3A and 7A). This is analogous to partial loss-of-function mutations in CYP11A1, which give rise to adrenal insufficiency in humans; the proteins may retain $30-40 \%$ of wild-type activity this is insufficient to maintain normal cortisol production (Parajes et al. 2011).

In contrast the intermediate steps of steroidogenesis occur in the ER, once pregnenolone is synthesized it undergoes reactions catalysed by $3 \beta$-hydroxysteroid dehydrogenase (Hsd3b2) and 21-hydroxylase (Cyp21a1) to produce progesterone and deoxycorticosterone respectively (Fig. 7B). No significant changes were observed at mRNA or protein level in these enzymes between $\mathrm{Nnt}^{-1-}$ vs $\mathrm{N}^{+/++}$mice, suggesting that mitochondrial ROS does not affect them and that a reduction of these enzymes is not the reason for their corticosterone deficiency (Fig. 7A and C).

\section{Transcriptomics-differentially expressed genes}

In total 400 genes were differentially expressed in pairwise analyses between the mouse substrains (Supplementary Table 2). Differentially expressed genes between $\mathrm{Nnt}^{+/+}$ vs $\mathrm{N}^{-1-}$ numbered 187 (89 up and 98 downregulated), between $N n t^{-/-}$vs $N n t^{B A C}$ numbered 157 (130 up- and 37 downregulated) and between $N n t^{+/+}$vs $N n t^{B A C}$ numbered 141 (119 up- and 22 downregulated) (Supplementary Tables 3, 4, 5, 6, 7 and 8).

We hypothesized that genes with altered expression

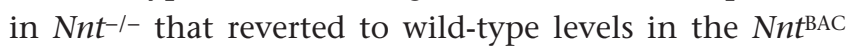
would be genes that were modulated by Nit levels. 40 genes including $\mathrm{N} n t$ were altered in $\mathrm{N}^{-1-}$ with their expression levels rescued in $N n t^{\mathrm{BAC}} .23$ of these were downregulated in $N n t^{-/-}$and back up in $N n t^{\mathrm{BAC}}$, while 17 were upregulated in $N n t^{-1-}$ and back down in $N n t^{\mathrm{BAC}}$ (Table 1). Two groups of genes were enriched in this list; chaperones and haemoglobins. Specifically, there was a 25-fold increase in Hspa1a and Hspa1b in $\mathrm{Nnt}^{-1-}$ mice,
Table 1 Forty genes modulated by NNT levels.

\begin{tabular}{|c|c|}
\hline \multicolumn{2}{|c|}{ Genes downregulated in $\mathrm{Nnt}^{-I_{-}^{-}}$and restored in $\mathrm{Nnt}^{\mathrm{BAC}}$} \\
\hline Gene ID & Gene description \\
\hline 1500015010Rik & RIKEN cDNA 1500015010 gene \\
\hline 9330151L19Rik & $\begin{array}{l}\text { ENSMUSG00000097061 - uncharacterized } \\
\text { protein }\end{array}$ \\
\hline A530020G20Rik & RIKEN CDNA A530020G20 gene \\
\hline C1qtnf6 & $\begin{array}{l}\text { C1q and tumour necrosis factor related } \\
\text { protein } 6\end{array}$ \\
\hline Ccdc160 & Coiled-coil domain containing 160 \\
\hline Ctxn3 & Cortexin 3 \\
\hline Cyp21a2-ps & Cyp21a2 pseudogene \\
\hline E330017L17Rik & RIKEN CDNA E330017L17 gene \\
\hline Epb4.114aos & $\begin{array}{l}\text { Erythrocyte membrane protein band } 4.1 \\
\text { like } 4 a \text {, opposite strand }\end{array}$ \\
\hline Gnat2 & $\begin{array}{l}\text { Guanine nucleotide binding protein, alpha } \\
\text { transducing } 2\end{array}$ \\
\hline Ism 1 & Isthmin 1 homolog (zebrafish) \\
\hline Kcnn2 & $\begin{array}{l}\text { Potassium intermediate/small conductance } \\
\text { calcium-activated channel, subfamily N, } \\
\text { member } 2\end{array}$ \\
\hline Lilr4b & $\begin{array}{l}\text { Leukocyte immunoglobulin-like receptor, } \\
\text { subfamily B, member 4B }\end{array}$ \\
\hline Ly96 & Lymphocyte antigen 96 \\
\hline Nnt & Nicotinamide nucleotide transhydrogenase \\
\hline Pacsin3 & $\begin{array}{l}\text { Protein kinase } C \text { and casein kinase substrate } \\
\text { in neurons } 3\end{array}$ \\
\hline Sox12 & SRY-box containing gene 12 \\
\hline Steap1 & $\begin{array}{l}\text { Six transmembrane epithelial antigen of } \\
\text { the prostate } 1\end{array}$ \\
\hline Trim12c & Tripartite motif-containing $12 \mathrm{C}$ \\
\hline Trim21 & Tripartite motif-containing 21 \\
\hline Trim30d & Tripartite motif-containing 30D \\
\hline Tuft1 & Tuftelin 1 \\
\hline Vsnl1 & Visinin-like 1 \\
\hline
\end{tabular}

Genes upregulated in $\mathrm{Nnt}^{-/-}$and restored in $\mathrm{Nnt}^{\mathrm{BAC}}$

Arl4d ADP-ribosylation factor-like 4D

Cwc25 CWC25 spliceosome-associated protein homolog (S. cerevisiae)

Cyr61 Cysteine rich protein 61

Dnajb1 DnaJ (Hsp40) homolog, subfamily B, member 1

Egr1 Early growth response 1

Fam46a Family with sequence similarity 46, member A

Gadd45g Growth arrest and DNA-damage-inducible 45 gamma

Hba-a1 Hemoglobin alpha, adult chain 1

Hba-a2 Hemoglobin alpha, adult chain 2

Hbb-bs Hemoglobin, beta adult s chain

Hbb-bt Hemoglobin, beta adult t chain

ler2 Immediate early response 2

ler3 Immediate early response 3

Irs2 Insulin receptor substrate 2

KIf4 Kruppel-like factor 4 (gut)

Nr4a2 Nuclear receptor subfamily 4, group A, member 2

Zfp36I2 Zinc finger protein 36, C3H type-like 2 
and these levels were restored to $N n t^{+/+}$levels in the $N n t^{\mathrm{BAC}}$ mice. A smaller, but still significant, increase was observed in another heat shock (Hspb1) and a co-chaperone (Dnajb1) in $\mathrm{Nnt}^{-/-}$mice (Fig. 8A).

The upregulation of heat shock proteins suggests that proteins are undergoing damage due to increased ROS and the molecular chaperone machinery is activated to correct or degrade such damaged or misfolded proteins. Interestingly alpha- and beta-haemoglobins (Hba-a1, $H b a-a 2, H b b-b 1$ and Hbb-b2 ( $a k a H b b-b s$ and Hbb-bt))

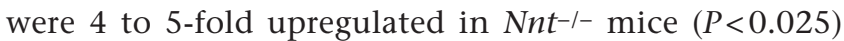
and their levels returned to normal in $N n t^{\mathrm{BAC}}$ (Fig. 8B). Erythroid contamination of the tissues from $\mathrm{Nnt}^{-/-}$ mice was considered but ruled out as other genes highly expressed in the development of erythroid lineages were not significantly upregulated $(51$ genes from
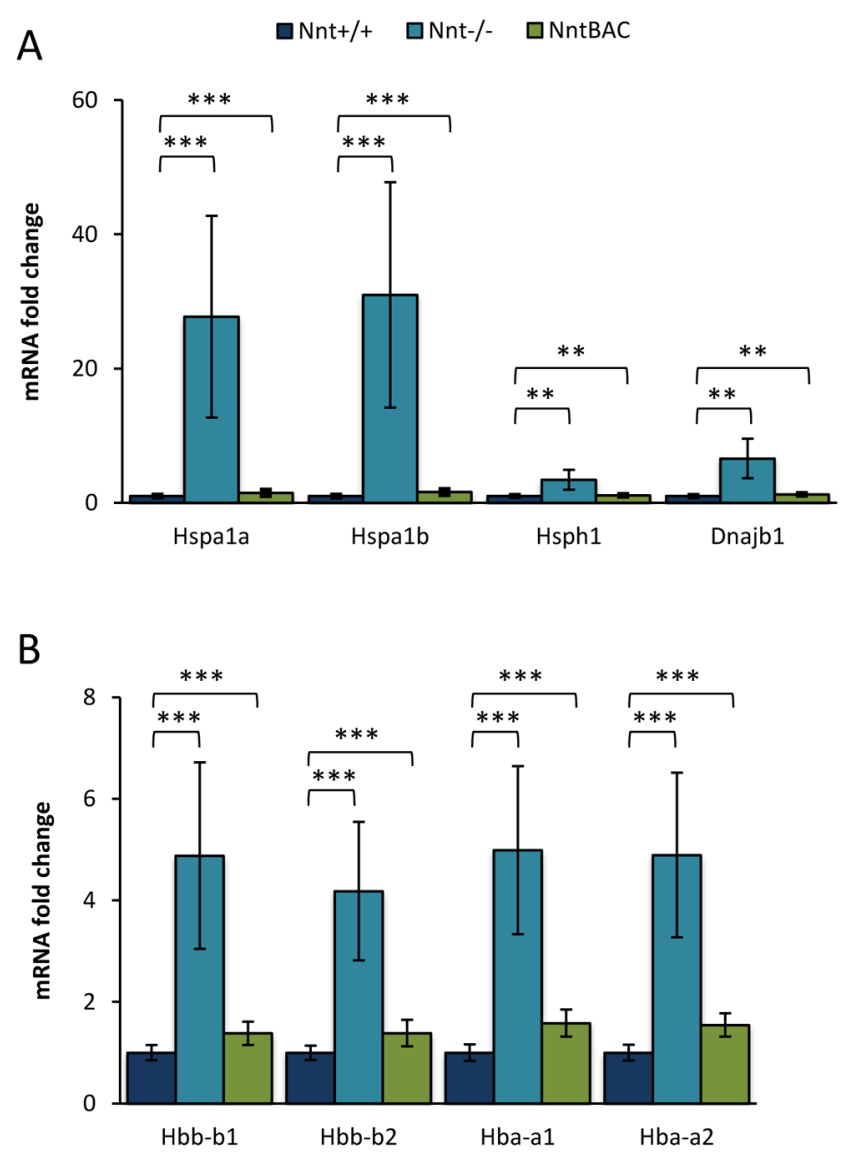

Figure 8

Enrichment of gene pathways in response to oxidative stress. (A) mRNA levels of heat shock proteins revealed significant upregulation (Hspa1a 26-fold; Hspa1a 25-fold; Hsph1 3-fold; Dnajb1 6-fold) in $\mathrm{Nnt}^{-1-}$ mice and restoration of the levels in $N n t^{B A C}$ mouse adrenals. (B) Similarly haemoglobin gene mRNA expression was significantly upregulated in $\mathrm{Nnt}^{-1-}$ mice when compared to $\mathrm{Nnt}^{+/+}$and reversed in $\mathrm{Nnt} \mathrm{BAC}^{\mathrm{A}}(\mathrm{Hbb}-\mathrm{b} 1$ 4-fold; Hbb-b2 5-fold; Hba-a1 5-fold; Hba-a2 5-fold).
An et al. 2014). Recently the expression of haemoglobins in tissues other than erythrocytes has been reported suggesting their role in other basic cellular functions apart from $\mathrm{O}_{2}$ transport (Fordel et al. 2006, Vinogradov $\&$ Moens 2008).

\section{Discussion}

We have previously shown that mutations in NNT cause adrenal dysfunction in humans primarily affecting the ZF cells of the adrenal cortex responsible for cortisol production, and observed a $50 \%$ reduction in corticosterone levels in 3-month-old Nnt null mice (Meimaridou et al. 2012). Further, we showed mitochondrial perturbations and limited antioxidant capacity in human adrenocortical carcinoma cells where NNT expression was stably knocked down (Meimaridou et al. 2012). In this study, we investigated the mechanism by which NNT affects steroidogenesis in older mice by utilising three models with differing expression levels of $\mathrm{Nnt}$; wild-type $\mathrm{Nnt}^{+/+}$, null $\mathrm{Nnt}^{-1-}$ and two-fold overexpressing ${\mathrm{N} n t^{B A C}}^{\mathrm{BA}}$ mice. Gene expression and Western blotting analysis revealed restricted levels of key mitochondrial antioxidant and steroidogenic proteins in $\mathrm{N}^{-1-}$ mice leading to glucocorticoid deficiency, which was partially rescued in the overexpressing mice. Interestingly, we demonstrate for the first time that overexpression of Nnt also negatively impacts steroidogenesis; this may be due to a persistent redox imbalance initiated by the oversupply of NADPH by NNT.

The mouse inbred C57BL/6 strain is widely used for genetic and functional studies. There are two substrains of these mice depending on their site of origin; C57BL/6J established in Jackson laboratory and C57BL/6N line from the National Institutes of Health (NIH). In 2005, a spontaneous loss-of-function Nht mutation in C57BL/6J was characterised, which was associated with impaired glucose tolerance (Ronchi et al. 2016). Since then, these mice have been used to clarify the roles of NNT in mammalian biology.

More recently, comparative genomics between C57BL/6J and C57BL/6N strains has identified many SNPs and structural variants that may contribute to the phenotypic differences between the two strains (24). We compared expression levels of the genes noted in this publication but revealed no differences in mRNA levels exception for Nnt. This suggests that the transcriptome changes and the endocrine phenotype observed in $\mathrm{Nnt}^{-/-}$ mice is largely due to differential NNT levels.

This work is licensed under a Creative Commons Attribution 3.0 Unported License. 
In this study, we have employed, in addition, a mouse strain with transgenic rescue of $N n t$ expression $\left(N n t^{B A C}\right)$ (Freeman et al. 2006). The Nnt replacement has previously been shown to induce improvements in glucose tolerance and insulin secretion rescuing the phenotype seen in $\mathrm{Nnt}^{-/-}$mice. Corticosterone levels recovered somewhat in the $N n t^{B A C}$; however, they remained significantly lower than wild-type levels.

In this in vivo model, we also showed that the antioxidant capacity of the $\mathrm{Nnt}^{-/-}$adrenals is significantly

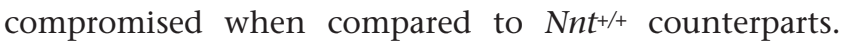
The protein levels of key mitochondrial antioxidant enzymes PRDX3 and TXNRD2 are significantly reduced

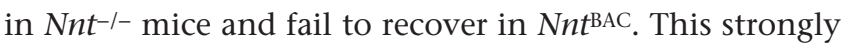
suggests that a set level of Nnt expression is required to maintain mitochondrial redox homeostasis. Furthermore, since mitochondrial NADPH can be regenerated not only by Nnt, but also by isocitrate dehydrogenase 2 (Idh2) and malic enzyme 3 (Me3), we excluded a possible compensatory mechanism, as expression levels of these enzymes remain unchanged between $\mathrm{Nnt}^{+/+}$and $\mathrm{Nnt}^{-I_{-}}$ mice. Studies by other groups have similarly demonstrated that liver, heart, brain and skeletal muscle mitochondria

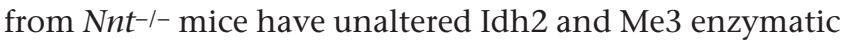
activities meaning they cannot compensate for the loss of NNT to restore NADPH levels (Nickel et al. 2015, Ronchi et al. 2016). When NNT is ablated in human adrenocortical cells, we also see a disturbance of redox balance, but here this does not affect cortisol output, perhaps due to adaptive alterations in sulfiredoxin and peroxiredoxin III levels, which are known to occur in H295R cells, and even primary adrenocortical cells, when grown in culture (Kil et al. 2013).

NNT dysregulation not only affects the antioxidant capacity of the adrenal but also its steroidogenic capacity. We demonstrated that, in $N n t^{-1-}$ mice, adrenal steroidogenesis is severely affected (86\% reduction in corticosterone in 18 months old mice), due to the low protein levels of a crucial steroidogenic enzyme, CYP11A1. Interestingly, $N n t^{\mathrm{BAC}}$ mice also exhibit glucocorticoid deficiency as indicated by $60 \%$ reduction in levels of corticosterone suggesting that Nnt overexpression also impacts on the steroidogenic output of these mice. It is increasingly recognised that redox balance is key to physiological health. Where one might assume that underexpression of antioxidants would lead to oxidative stress and overexpression would give reductive stress; this is not necessarily what occurs in vivo (reviewed in Lei et al. 2016), with clear examples of antioxidant gene knockdown inducing reductive stress (Yan et al. 2017) and antioxidant gene overexpression also causing reductive stress (Zhang et al. 2010). In addition, paradoxically, both reductive and oxidative insult can lead to overproduction of ROS (Barrett et al. 2004, Arrigo et al. 2005, Filomeni et al. 2005, Ali et al. 2014, Yu et al. 2014, Korge et al. 2015), which can cause protein damage. We suggest that this may be the explanation for the failure to rescue glucocorticoid secretion in the overexpressing mice with the demonstration of higher levels of lipid peroxidation in the $\mathrm{Nnt}^{\mathrm{BAC}}$ mice compared to $\mathrm{Nnt}^{+/+}$mice lending support to this.

Differential gene expression studies between ${\mathrm{N} n \mathrm{t}^{+/+}}$and $\mathrm{N} n \mathrm{t}^{-/-}$revealed a significant upregulation of heat shock proteins in $N n t^{-1-}$ mice. The failure of ROS detoxification may lead to oxidative damage of proteins and the canonical chaperone machinery will be upregulated to cope with the resultant protein misfolding and degradation. The increased ROS will also render cells more susceptible to apoptosis but heat shock proteins 27 and 70 (Hsp27 and Hsp70 respectively) are activated by mitochondrial ROS and are protective of cells preventing apoptosis by replenishing reduced glutathione and reducing intracellular iron levels (Barrett et al. 2004, Arrigo et al. 2005, Filomeni et al. 2005).

In addition to heat shock protein machinery, we show haemoglobins are regulated by NNT levels. There is a significant increase in the mRNA levels of haemoglobins in $\mathrm{N}^{-1-}$ mice possibly as a compensatory mechanism to combat oxidative stress. Haemoglobins are composed of alpha and beta $\mathrm{HbA}$ chains and their accepted main function is to transport $\mathrm{O}_{2}$ to cells thorough the vascular network. However, their involvement in other fundamental cellular functions and in non-erythroid cells is increasingly being recognised. Detection of haemoglobin chains in macrophages, alveolar cells, kidney, brain and vaginal epithelial cells has been reported and their function has been linked with antioxidant defence and the regulation of mitochondrial activity (Liu et al. 1999, Arrigo et al. 2005, Newton et al. 2006, Nishi et al. 2008, Saha et al. 2017). In adrenal, overexpression of $\alpha-\mathrm{Hb}$ in rat phaeochromocytoma (PC12) cells resulted in downregulation of Gpx1 and Sod1 mRNAs suggesting that it may have a role in the scavenging of ROS (Biagioli et al. 2009, Maria et al. 2012). Whether a similar mechanism explains the upregulation we see in intact adrenals requires further investigation.

In this study, we showed that the reduced steroidogenic

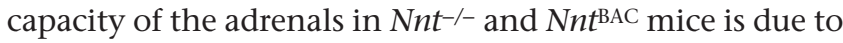
the inability of other antioxidant enzymes to compensate for redox imbalance resulting from altered Nnt levels. 
This leads to limited availability of mitochondrial CYP11A1 and a reduction in corticosterone output. Recently a similar mechanism was demonstrated to underlie the adrenal dysfunction seen in Triple A, a disorder of adrenal insufficiency, alacrima and achalasia due to mutations in $A A A S$ encoding the protein ALADIN. A deficiency of ALADIN results in cytosolic, as opposed to mitochondrial, oxidative stress and a deficit of microsomal, rather than mitochondrial, CYP450 enzymes thereby retarding adrenal steroidogenesis (Juhlen et al. 2015).

\section{Conclusions}

Using transcriptomic profiling in adrenals from three mouse substrains, we showed that disturbances in adrenal redox homeostasis are mediated not only by under expression of NNT but also by its overexpression. Further, we demonstrated that both underexpression or overexpression of NNT reduces corticosterone output implying a central role for it in the control of steroidogenesis. Reduced expression of CYP11A1, a key mitochondrial steroidogenic enzyme, mirrored the reduction in corticosterone output. Our data also suggest that oxidative stress and/or ROS damage to proteins is activating mito- and cytoprotective proteins (haemoglobins and heat shock proteins respectively) that may help maintain cell viability but do not rescue the steroidogenic phenotype.

\section{Supplementary data}

This is linked to the online version of the paper at $\mathrm{http}: / / \mathrm{dx}$.doi.org/10.1530/ JOE-16-0638.

\section{Declaration of interest}

The authors declare that there is no conflict of interest that could be perceived as prejudicing the impartiality of the research reported.

\section{Funding}

This work has been supported by the Medical Research Council UK (Project Grant MR/K020455/1, to L A M), (Project Grant MC_U142661184, to R C) and the Wellcome Trust (Clinical Research Training Fellowship WT101671, to $\mathrm{V}$ C).

\section{Author contribution statement}

E M, L A M designed the study and analysed the RNA-seq data. E M and $F$ E performed the immunoblotting and mouse histology. M G and
R C generated and validated mouse substrains. V C, P A F and W A performed the steroidogenic profiling of mice and analysed the mass spectrometric data. E M and L A M prepared the draft manuscript. All authors contributed to the discussion of results and edited and approved the final manuscript.

\section{References}

Ali ZA, de Jesus Perez V, Yuan K, Orcholski M, Pan S, Qi W, Chopra G, Adams C, Kojima Y, Leeper NJ, et al. 2014 Oxido-reductive regulation of vascular remodeling by receptor tyrosine kinase ROS1. Journal of Clinical Investigation 124 5159-5174. (https://doi.org/10.1172/ JCI77484)

An X, Schulz VP, Li J, Wu K, Liu J, Xue F, Hu J, Mohandas N \& Gallagher PG 2014 Global transcriptome analyses of human and murine terminal erythroid differentiation. Blood 123 3466-3477. (https://doi.org/10.1182/blood-2014-01-548305)

Arrigo AP, Virot S, Chaufour S, Firdaus W, Kretz-Remy C \& DiazLatoud C 2005 Hsp27 consolidates intracellular redox homeostasis by upholding glutathione in its reduced form and by decreasing iron intracellular levels. Antioxidants and Redox Signaling 7 414-422. (https://doi.org/10.1089/ars.2005.7.414)

Baker B, Lin L, Kim C, Raza J, Smith C, Miller W \& Achermann J 2006 Nonclassic congenital lipoid adrenal hyperplasia: a new disorder of the steriodogenic acute regulatory protein with very late presentation and normal male genitalia. Journal of Clinical Endocrinology and Metabolism 91 4781-4785. (https://doi.org/10.1210/jc.2006-1565)

Barrett MJ, Alones V, Wang KX, Phan L \& Swerdlow RH 2004 Mitochondria-derived oxidative stress induces a heat shock protein response. Journal of Neuroscience Research 78 420-429. (https://doi. org/10.1002/jnr.20249)

Biagioli M, Pinto M, Cesselli D, Zaninello M, Lazarevic D, Roncaglia P, Simone R, Vlachouli C, Plessy C, Bertin N, et al. 2009 Unexpected expression of alpha- and beta-globin in mesencephalic dopaminergic neurons and glial cells. PNAS 106 15454-15459. (https://doi. org/10.1073/pnas.0813216106)

Chida D, Nakagawa S, Nagai S, Sagara H, Katsumata H, Imaki T, Suzuki H, Mitani F, Ogishima T, Shimizu C, et al. 2007 Melanocortin 2 receptor is required for adrenal gland development, steroidogenesis, and neonatal gluconeogenesis. PNAS 104 18205-18210. (https://doi. org/10.1073/pnas.0706953104)

Chida D, Sato T, Sato Y, Kubo M, Yoda T, Suzuki H \& Iwakura Y 2009 Characterization of mice deficient in melanocortin 2 receptor on a B6/Balbc mix background. Molecular and Cellular Endocrinology 300 32-36. (https://doi.org/10.1016/j.mce.2008.10.027)

Diemer T, Allen JA, Hales KH \& Hales DB 2003 Reactive oxygen disrupts mitochondria in MA-10 tumor Leydig cells and inhibits steroidogenic acute regulatory (StAR) protein and steroidogenesis. Endocrinology 144 2882-2891. (https://doi.org/10.1210/en.2002-0090)

Filomeni G, Aquilano K, Rotilio G \& Ciriolo MR 2005 Antiapoptotic response to induced GSH depletion: involvement of heat shock proteins and NF-kappaB activation. Antioxidants and Redox Signaling 7 446-455. (https://doi.org/10.1089/ars.2005.7.446)

Fordel E, Thijs L, Martinet W, Lenjou M, Laufs T, Van Bockstaele D, Moens L \& Dewilde S 2006 Neuroglobin and cytoglobin overexpression protects human SH-SY5Y neuroblastoma cells against oxidative stress-induced cell death. Neuroscience Letters 410 146-151. (https://doi.org/10.1016/j.neulet.2006.09.027)

Freeman HC, Hugill A, Dear NT, Ashcroft FM \& Cox RD 2006 Deletion of nicotinamide nucleotide transhydrogenase: a new quantitative trait locus accounting for glucose intolerance in C57BL/6J mice. Diabetes 55 2153-2156. (https://doi.org/10.2337/db06-0358)

Guasti L, Paul A, Laufer E \& King P 2011 Localization of Sonic hedgehog secreting and receiving cells in the developing and adult rat adrenal cortex. Molecular and Cellular Endocrinology 336 117-122. (https://doi. org/10.1016/j.mce.2010.11.010) 
Huang TT, Naeemuddin M, Elchuri S, Yamaguchi M, Kozy HM, Carlson EJ \& Epstein CJ 2006 Genetic modifiers of the phenotype of mice deficient in mitochondrial superoxide dismutase. Human Molecular Genetics 15 1187-1194. (https://doi.org/10.1093/hmg/ddl034)

Jühlen R, Idkowiak J, Taylor AE, Kind B, Arlt W, Huebner A \& Koehler K 2015 Role of ALADIN in human adrenocortical cells for oxidative stress response and steroidogenesis. PLOS ONE 10 e0124582. (https://doi.org/10.1371/journal.pone.0124582)

Keller-Wood ME \& Dallman MF 1984 Corticosteroid inhibition of ACTH secretion. Endocrine Reviews 5 1-24. (https://doi.org/10.1210/ edrv-5-1-1)

Kil IS, Bae SH \& Rhee SG 2013 Study of the signaling function of sulfiredoxin and peroxiredoxin III in isolated adrenal gland: unsuitability of clonal and primary adrenocortical cells. Methods in Enzymology 527 169-181. (https://doi.org/10.1016/B978-0-12-4058828.00009-X)

Korge P, Calmettes G \& Weiss JN 2015 Increased reactive oxygen species production during reductive stress: the roles of mitochondrial glutathione and thioredoxin reductases. Biochimica et Biophysica Acta 1847 514-525. (https://doi.org/10.1016/j.bbabio.2015.02.012)

Lei XG, Zhu JH, Cheng WH, Bao Y, Ho YS, Reddi AR, Holmgren A \& Arnér ES 2016 Paradoxical roles of antioxidant enzymes: basic mechanisms and health implications. Physiological Reviews 96 307-364. (https://doi.org/10.1152/physrev.00010.2014)

Liu L, Zeng M \& Stamler JS 1999 Hemoglobin induction in mouse macrophages. PNAS 96 6643-6647. (https://doi.org/10.1073/ pnas.96.12.6643)

Marcos-Almaraz MT, Rodríguez-Gómez JA, López-Barneo J \& Pascual A $2012 \alpha$-Haemoglobin regulates sympathoadrenal cell metabolism to maintain a catecholaminergic phenotype. Biochemical Journal 441 843-852. (https://doi.org/10.1042/BJ20111640)

Meimaridou E, Kowalczyk J, Guasti L, Hughes CR, Wagner F, Frommolt P, Nürnberg P, Mann NP, Banerjee R, Saka HN, et al. 2012 Mutations in NNT encoding nicotinamide nucleotide transhydrogenase cause familial glucocorticoid deficiency. Nature Genetics 44 740-742. (https://doi.org/10.1038/ng.2299)

Meimaridou E, Hughes CR, Kowalczyk J, Chan LF, Clark AJ \& Metherell LA 2013 ACTH resistance: genes and mechanisms. Endocrine Development 24 57-66. (https://doi.org/10.1159/000342504)

Metherell LA, Naville D, Halaby G, Begeot M, Huebner A, Nürnberg G, Nürnberg P, Green J, Tomlinson JW, Krone NP, et al. 2009 Nonclassic lipoid congenital adrenal hyperplasia masquerading as familial glucocorticoid deficiency. Journal of Clinical Endocrinology and Metabolism 94 3865-3871. (https://doi.org/10.1210/jc.2009-0467)

Miller WL \& Auchus RJ 2011 The molecular biology, biochemistry, and physiology of human steroidogenesis and its disorders. Endocrine Reviews 32 81-151. (https://doi.org/10.1210/er.2010-0013)

Newton DA, Rao KM, Dluhy RA \& Baatz JE 2006 Hemoglobin is expressed by alveolar epithelial cells. Journal of Biological Chemistry $\mathbf{2 8 1}$ 5668-5676. (https://doi.org/10.1074/jbc.M509314200)

Nickel AG, von Hardenberg A, Hohl M, Löffler JR, Kohlhaas M, Becker J, Reil JC, Kazakov A, Bonnekoh J, Stadelmaier M, et al. 2015 Reversal of mitochondrial transhydrogenase causes oxidative stress in heart failure. Cell Metabolism 22 472-484. (https://doi.org/10.1016/j. cmet.2015.07.008)

Nishi H, Inagi R, Kato H, Tanemoto M, Kojima I, Son D, Fujita T \& Nangaku M 2008 Hemoglobin is expressed by mesangial cells and reduces oxidant stress. Journal of the American Society of Nephrology 1500-1508. (https://doi.org/10.1681/ASN.2007101085)

Nishimoto K, Rigsby CS, Wang T, Mukai K, Gomez-Sanchez CE, Rainey WE \& Seki T 2012 Transcriptome analysis reveals differentially expressed transcripts in rat adrenal zona glomerulosa and zona fasciculata. Endocrinology 153 1755-1763. (https://doi.org/10.1210/ en.2011-1915)

O'Reilly MW, Taylor AE, Crabtree NJ, Hughes BA, Capper F, Crowley RK, Stewart PM, Tomlinson JW \& Arlt W 2014
Hyperandrogenemia predicts metabolic phenotype in polycystic ovary syndrome: the utility of serum androstenedione. Journal of Clinical Endocrinology and Metabolism 99 1027-1036. (https://doi org/10.1210/jc.2013-3399)

Parajes S, Kamrath C, Rose IT, Taylor AE, Mooij CF, Dhir V, Grötzinger J, Arlt W \& Krone N 2011 A novel entity of clinically isolated adrenal insufficiency caused by a partially inactivating mutation of the gene encoding for P450 side chain cleavage enzyme (CYP11A1). Journal of Clinical Endocrinology and Metabolism 96 E1798-E1806. (https://doi. org/10.1210/jc.2011-1277)

Prasad R, Chan LF, Hughes CR, Kaski JP, Kowalczyk JC, Savage MO, Peters CJ, Nathwani N, Clark AJ, Storr HL, et al. 2014 Thioredoxin reductase 2 (TXNRD2) mutation associated with familial glucocorticoid deficiency (FGD). Journal of Clinical Endocrinology and Metabolism 99 E1556-E1563. (https://doi.org/10.1210/jc.2013-3844)

Rege J, Nakamura Y, Wang T, Merchen TD, Sasano H \& Rainey WE 2014 Transcriptome profiling reveals differentially expressed transcripts between the human adrenal zona fasciculata and zona reticularis. Journal of Clinical Endocrinology and Metabolism 99 E518-E527. (https://doi.org/10.1210/jc.2013-3198)

Ronchi JA, Figueira TR, Ravagnani FG, Oliveira HC, Vercesi AE \& Castilho RF 2013 A spontaneous mutation in the nicotinamide nucleotide transhydrogenase gene of $\mathrm{C} 57 \mathrm{BL} / 6 \mathrm{~J}$ mice results in mitochondrial redox abnormalities. Free Radical Biology and Medicine 63 446-456. (https://doi.org/10.1016/j. freeradbiomed.2013.05.049)

Ronchi JA, Francisco A, Passos LA, Figueira TR \& Castilho RF 2016 The contribution of nicotinamide nucleotide transhydrogenase to peroxide detoxification is dependent on the respiratory state and counterbalanced by other sources of NADPH in liver mitochondria. Journal of Biological Chemistry 291 20173-20187. (https://doi. org/10.1074/jbc.M116.730473)

Rubtsov P, Karmanov M, Sverdlova P, Spirin P \& Tiulpakov A 2009 A novel homozygous mutation in CYP11A1 gene is associated with late-onset adrenal insufficiency and hypospadias in a 46,XY patient. Journal of Clinical Endocrinology and Metabolism 94 936-939. (https://doi.org/10.1210/jc.2008-1118)

Saha D, Koli S \& Reddy KVR 2017 Transcriptional regulation of $\mathrm{Hb}-\alpha$ and $\mathrm{Hb}-\beta$ through nuclear factor E2-related factor-2 (Nrf2) activation in human vaginal cells: a novel mechanism of cellular adaptability to oxidative stress. American Journal of Reproductive Immunology $\mathbf{7 7}$ [epub]. (https://doi.org/10.1111/aji.12645)

Sahakitrungruang T, Soccio RE, Lang-Muritano M, Walker JM, Achermann JC \& Miller WL 2010 Clinical, genetic, and functional characterization of four patients carrying partial loss-of-function mutations in the steroidogenic acute regulatory protein (StAR) Journal of Clinical Endocrinology and Metabolism 95 3352-3359. (https://doi.org/10.1210/jc.2010-0437)

Sahakitrungruang T, Tee MK, Blackett PR \& Miller WL 2011 Partial defect in the cholesterol side-chain cleavage enzyme P450scc (CYP11A1) resembling nonclassic congenital lipoid adrenal hyperplasia. Journal of Clinical Endocrinology and Metabolism 96 792-798. (https://doi. org/10.1210/jc.2010-1828)

Sasaki G, Ishii T, Jeyasuria P, Jo Y, Bahat A, Orly J, Hasegawa T \& Parker KL 2008 Complex role of the mitochondrial targeting signal in the function of steroidogenic acute regulatory protein revealed by bacterial artificial chromosome transgenesis in vivo. Molecular Endocrinology 22 951-964. (https://doi.org/10.1210/me.2007-0493)

Sauer U, Canonaco F, Heri S, Perrenoud A \& Fischer E 2004 The soluble and membrane-bound transhydrogenases UdhA and PntAB have divergent functions in NADPH metabolism of Escherichia coli. Journal of Biological Chemistry 279 6613-6619. (https://doi.org/10.1074/jbc. M311657200)

Simon MM, Greenaway S, White JK, Fuchs H, Gailus-Durner V, Wells S, Sorg T, Wong K, Bedu E, Cartwright EJ, et al. 2005 A genetic and physiological study of impaired glucose homeostasis control in

This work is licensed under a Creative Common Attribution 3.0 Unported License. 
C57BL/6J mice. Diabetologia 48 675-686. (https://doi.org/10.1007/ s00125-005-1680-z)

Simon MM, Greenaway S, White JK, Fuchs H, Gailus-Durner V, Wells S, Sorg T, Wong K, Bedu E, Cartwright EJ, et al. 2013 A comparative phenotypic and genomic analysis of C57BL/6J and C57BL/6N mouse strains. Genome Biology 14 R82.

Toye AA, Lippiat JD, Proks P, Shimomura K, Bentley L, Hugill A, Mijat V, Goldsworthy M, Moir L, Haynes A, et al. 2005 A genetic and physiological study of impaired glucose homeostasis control in C57BL/6J mice. Diabetologia 48 675-686.

Roberson LA, Rozman J, Sanderson M, Santos L, Selloum M, Shannon C, Southwell A, Tocchini-Valentini GP, Vancollie VE, Westerberg H, et al. 2013 A comparative phenotypic and genomic analysis of C57BL/6 and C57BL/6N mouse strains. Genome Biology 14 R82. (https://doi. org/10.1186/gb-2013-14-7-r82)

Trapnell C, Hendrickson DG, Sauvageau M, Goff L, Rinn JL \& Pachter L 2013 Differential analysis of gene regulation at transcript resolution with RNA-seq. Nature Biotechnology 31 46-53. (https://doi. org/10.1038/nbt.2450)
Vinogradov SN \& Moens L 2008 Diversity of globin function: enzymatic, transport, storage, and sensing. Journal of Biological Chemistry 283 8773-8777. (https://doi.org/10.1074/jbc.R700029200)

Vinson GP 2003 Adrenocortical zonation and ACTH. Microscopy Research and Technique 61 227-239. (https://doi.org/10.1002/jemt.10331)

Yan J, Guo Y, Fei Y, Zhang R, Han Y \& Lu S 2017 GPx1 knockdown suppresses chondrogenic differentiation of ATDC5 cells through induction of reductive stress. Acta Biochimica et Biophysica Sinica 49 110-118. (https://doi.org/10.1093/abbs/gmw125)

Yu Q, Lee CF, Wang W, Karamanlidis G, Kuroda J, Matsushima S, Sadoshima J \& Tian R 2014 Elimination of NADPH oxidase activity promotes reductive stress and sensitizes the heart to ischemic injury. Journal of the American Heart Association 3 e000555. (https://doi. org/10.1161/JAHA.113.000555)

Zhang X, Min X, Li C, Benjamin IJ, Qian B, Zhang X, Ding Z, Gao X, Yao Y, Ma Y, et al. 2010 Involvement of reductive stress in the cardiomyopathy in transgenic mice with cardiac-specific overexpression of heat shock protein 27. Hypertension $\mathbf{5 5}$ 1412-1417. (https://doi.org/10.1161/HYPERTENSIONAHA.109.147066)

Received in final form 29 September 2017

Accepted 18 October 2017

Accepted Preprint published online 18 October 2017
This work is licensed under a Creative Commons Attribution 3.0 Unported License. 